\title{
Calibration of Forest Chemistry for Hyperspectral Analysis
}

\author{
David G. Goodenough ${ }^{1,2}$, A. S. (Pal) Bhogal ${ }^{1}$, Andrew Dyk ${ }^{1}$, Olaf Niemann ${ }^{3}$, Tian Han $^{2}$, Hao Chen ${ }^{2}$, \\ Chris West ${ }^{1,2}$, and Chris Schmidt ${ }^{1,2}$ \\ ${ }^{1}$ Pacific Forestry Centre, Natural Resources Canada \\ ${ }^{2}$ Department of Computer Science, University of Victoria \\ ${ }^{3}$ Department of Geography, University of Victoria \\ 506 West Burnside Road, Victoria, BC, Canada, V8Z 1M5 \\ (250-363-0776, office; 250-363-0775, fax); dgoodeno@ nrcan.gc.ca
}

\begin{abstract}
A primary advantage of hyperspectral sensors is the ability to provide measurements of canopy chemistry. Canopy chemistry can be used to estimate new and old foliage, detect damage, identify trees under stress, and map chemical distributions in the forests. We have begun a new EO-1 project, Evaluation and Validation of EO-1 for Sustainable Development of forests (EVEOSD). NASA's EO-1 satellite was successfully launched on November 21, 2000. In preparation for airborne and spaceborne data collection and calibration, we collected in September 2000 foliar canopy and ground cover chemistry samples from 54 plots distributed across the Greater Victoria Watershed (GVWD) test site. Treetop samples were collected from helicopters. Differential GPS was used to provide sample positioning to within $1 \mathrm{~m}$. The foliar samples were divided into new and old foliage. Organic and inorganic chemistry analyses were done. Spectral calibration samples were collected over ground targets, over stacks of foliar samples, and over ground vegetation. Landsat-7 and Radarsat data were collected at the same time. The chemistry samples were placed into a database and integrated with GIS files of topography and forest cover. We obtained $1 \mathrm{~m}$ aerial orthophotography that allowed us to investigate the spectral components making up the Landsat-7 and EO- 1 pixels. This paper describes the experimental design and the ground and canopy chemistry. Examples of unique concentrations, such as high levels of arsenic in foliar samples, are shown spatially. Recommendations are made for experimental design for ground reference collection for hyperspectral calibration.
\end{abstract}

\section{INTRODUCTION}

A primary advantage of hyperspectral sensors is their ability to provide measurements of canopy chemistry. Canopy chemistry can be used to estimate new and old foliage, detect damage, identify trees under stress, and map chemical distributions in the forests. In 1993 and 1994 AVIRIS data were collected over the Greater Victoria Watershed (GVWD) test site on Vancouver Island, together with foliar chemical samples [1], [2]. In cooperation with NASA, we have begun a new project, Evaluation and Validation of EO-1 for Sustainable Development of forests
(EVEOSD). NASA's EO-1 satellite was successfully launched on November 21, 2000. Data collection by aircraft and satellite over GVWD will commence in June 2001.

In preparation for airborne and spaceborne data collection and calibration, we collected in September 2000 foliar canopy and ground cover chemistry samples from 54 plots distributed across the GVWD test site. Over 90 percent of the trees found in this test site are Douglas Fir. The average elevation of GVWD is about 400 meters above sea level, with slopes as great as 45 degrees for some of the plots. Except for the younger stands, the old growth forest in this test site is largely unmanaged, and most of our experimental plots are from unmanaged areas. The GVWD test site contains some of the oldest stands of Douglas Fir in the southern half of Vancouver Island. The foliar samples were divided into new and old foliage. Organic and inorganic chemistry analyses were performed. We used TRW's Analytical Spectral Devices ground spectrometer to collect spectral calibration samples over ground targets, over stacks of foliar samples, and over ground vegetation. Landsat-7 and Radarsat data were collected at the same time. The chemistry samples were placed into a database described below and integrated with GIS files for topography and forest cover. We obtained $1 \mathrm{~m}$ aerial orthophotography that allowed us to investigate the spectral components making up the Landsat-7 and EO-1 pixels.

\section{FIELD WORK DESIGN}

The 54 plots were selected to sample forest ages in a range of geomorphologic attributes within the bound of the study area. The plots were chosen to sample old growth, mature and immature Douglas Fir stands in a range of various slopes, aspects and elevations. Plots have also been set up to sample various fertilization treatments applied in earlier PFC test plots located in the northern portion of the study area.

All plots had treetop foliar samples collected from helicopter and where access was possible, we collected samples of the ground cover for chemical analysis. Most of the ground cover was salal. We had found from earlier analyzes that the chemistry of the ground cover confused the interpretations of the remote sensing hyperspectral data [3]. 
Fig. 1 shows the spatial distribution of the 54 plots for the GVWD. The test site boundary of $15 \mathrm{~km}$ by $23 \mathrm{~km}$ is shown in red. Those plots for which both tree top foliar samples and ground cover samples were collected are shown in yellow. Plots where only tree top samples were obtained are shown in green. A team that included industry, government and academics conducted the sampling, differential GPS measurements and chemical analyses. The tree top foliar samples were obtained from a helicopter since the trees were too tall to be climbed safely and quickly.

Four differential GPS units were rented and used to provide sample locations to within $1 \mathrm{~m}$, both from the helicopter and on the ground. Fig. 2 shows an example of such a collection for a single plot with the GIS objects overlaid on top of the $1 \mathrm{~m}$ ortho photo. As PFC has conducted research in the GVWD for more than 30 years, we obtained data collections by other research groups to support the EVEOSD project. Within the plot boundary shown in red every tree has been measured and geolocated. The plot center for EVEOSD is shown in yellow. The pink symbols denote the collection pattern for the 5 salal samples. The 10 tree top sample locations are shown in green. Center and north chronosequence (tree ring) plot monument locations are shown in yellow. At these points ground litter has also been analyzed. The road network is indicated and the point of commencement for ground access is shown. The tree top samples were divided into current and old foliage. The organic chemistry analyses were conducted at PFC. The inorganic chemistry analyses were conducted under contract. A database was created for the field data and has been populated with the chemistry results. Ground photos were taken at each plot. Five photos were taken at each plot, facing north, south, east, west, and plot center with numerical identifier. Photos were scanned digitally and added to the database.

A TRW ASD ground spectrometer and a CCRS GER 3700 spectrometer were used. Staff were trained in the operation of both instruments. At the test site 3,900 spectra were collected with the ASD instrument. We discovered that CCRS' GER 3700 was shipped to CCRS two years ago with an incorrect wavelength calibration table. This could not be fixed in the field and required the return of the instrument to the manufacturer. We, therefore, relied on only the ASD spectrometer. Measurements were made of ground calibration targets. We also made spectral measurements of stacks of salal in sunlight and in shade and stacks of Douglas fir foliage acquired from the tree tops.

\section{CHEMICAL AND SPECTRAL MEASUREMENTS}

The reflectance of visible light from vegetation is governed by a number of factors. For vegetation, the most important factor determining the reflectance is due to the chemical constituents in the foliage. Influence of the background (e.g. soil or salal) can be an important contributing factor to spectral reflectance. In [4] and [5] we demonstrated the confounding influence of ground cover for the extraction of forest biophysical attributes (such as crown closure) for the GVWD test site in AVIRIS data.

The red edge is the most dramatic signature of green vegetation due to chlorophyll absorption in the $680 \mathrm{~nm}$ to 900nm spectral range. The red edge may be quantified by a number of reflectances and their associated wavelengths [6], [7] including the baseline reflectance at $680 \mathrm{~nm}$, the NIR reflectance, the slope of the curve, and inflection points. These reflectances can be affected by vegetation state as well as canopy attributes such as crown closure, Leaf Area Index (LAI), and other factors such as fractional Photosynthetically Absorbed Radiation (fPAR).

For the current work, canopy and ground cover foliage sampling was carried out for 54 plots in our test site of GVWD. There were 10 samples collected per plot, and at each sample location, two samples of Douglas Fir (Pseudotsuga menziesii) foliage and twig samples were acquired. One sample was used for organic analysis (e.g. nitrogen, chlorophyll $\mathrm{a}$ and $\mathrm{b}$, moisture, etc.) and the remaining sample was used for inorganic analysis. Inorganic analysis of both the foliage and ground cover samples involved reduction of samples to ash, and digestion in an acid solution, followed by analytical determinations. Two batches of foliar samples were analyzed inorganically. The vast majority of the canopy foliar samples were from Douglas Fir subjected to analysis resulting in concentrations of 37 inorganic constituents. A smaller set of samples (10\%) was subjected to analysis for 63 constituents. Overall, 654 treetop foliar samples were collected for analysis, resulting in more than 26,000 analytical determinations for inorganic constituents by an independent laboratory (Actilabs). Several samples were also collected from other tree species and analyzed for inorganic constituents. In this paper, we focus on Douglas Fir and Salal (an evergreen broad-leafed brush which is the principal ground cover in the test site).

In support of the field chemistry program, spectral measurements were acquired. Spectral measurements were carried out over a 2-week period (September 112000 to September 23 2000) using the ASD field spectrometer. Foliar spectral targets included a stack of foliage from Douglas Fir, and a stack of salal, both in direct sunlight as well as shade. Other spectral endmembers included a field with various grass types, gravel and road targets, an asphalt parking lot, and a dark target (water in the deepest portion of Lake Shawnigan, which is adjacent to the test site). Readings from a standard white reference were used both in the laboratory and in the field to convert the spectral values to reflectance for each target. Endmember spectral profiles were computed by averaging 200 to 400 individual spectra from the ASD FieldSpec unit acquired over large homogeneous areas whenever possible. These averaged spectral profiles have formed the basis for the EVEOSD spectral library.

The spectral profiles of the foliar targets were analyzed in accordance with the Vclass method [6], and the red edge was 
quantified using the reflectances discussed above. This analysis was used to determine if the spectral profiles were well-behaved in accordance with a Gaussian formulation for spectra from both the field spectrometer and the AVIRIS sensor.

\section{EVEOSD ChEMICAL AND SPECTRAL DATABASE}

The EVEOSD Chemical and Spectral Database contains data collected from the Greater Victoria Watershed District (GVWD) during our September 2000 field program. Microsoft Access was used as the database management system because of its portability, and ease of use. The database contains twenty-five different tables containing data on canopy chemistry, ground chemistry, ground spectra and precision GPS. Table 1 lists the table names and the primary keys for these database tables.

Table 1. EVEOSD Chemical and Spectral Database relational tables and primary keys.

\begin{tabular}{|l|l|}
\hline Table Name & Primary Key(s) \\
\hline Conifer Chemistry & Plot Number,SSample Number \\
ES Different Species & \\
\hline $\begin{array}{l}\text { Conifer Inorganic Chemistry ICP- } \\
\text { ES Samples }\end{array}$ & Conifer_Inorganic_ICPESID \\
\hline $\begin{array}{l}\text { Conifer Inorganic Chemistry ICP- } \\
\text { MS Different Species }\end{array}$ & VarioustreesMSID \\
\hline $\begin{array}{l}\text { Conifer Inorganic Chemistry ICP- } \\
\text { MS Samples }\end{array}$ & ConiferICPMSID \\
\hline Current Conifer Chemistry & Current_Growth_ID \\
\hline Field Spectral Plot Data & Plot Number, Date \\
\hline Climate Data & Climate_ID \\
\hline Non-Current Conifer Chemistry & Non_Current_Growth_ID \\
\hline Plot Data & Plot_Number \\
\hline Plot Pictures & Plot_Picture_ID \\
\hline Point of Commencement & PoCID \\
\hline Salal Chemistry & Plot Number, Sample Number \\
\hline Salal Inorganic Chemistry & SalalInorganicID \\
\hline Spectra Radiance Data & RadianceID \\
\hline Spectra Reflectance Data & ReflectanceID \\
\hline Spectra Site Picture Data & Picture_DataID \\
\hline Spectra Directory Data & Excel_File_Name \\
\hline Weather Station Location & Location_Name \\
\hline Statistics Conifer Inorganic & Plot_Number \\
\hline Statistics Conifer Organic Current & Plot_Number \\
\hline $\begin{array}{l}\text { Statistics Conifer Organic Non- } \\
\text { current }\end{array}$ & Plot_Number \\
\hline Statistics Overall Salal Inorganic & ElementID \\
\hline Statistics Salal Inorganic & Plot_Number \\
\hline Statistics Salal Organic & Plot_Number \\
\hline & \\
\hline
\end{tabular}

A graphical user interface programmed in Visual Basic was created for the database which allows the user to access the data without having an intimate knowledge of relational databases. The interface contains embedded queries to provide summary tables and graphical spectra for userspecified sites and parameters.
Organic and inorganic data analyses were performed on salal and tree top samples. The organic chemical analysis conducted on the tree top samples was partitioned into current growth and non-current growth. Current growth is defined as any foliar growth that occurred within the last year. All other foliar growth is considered to be non-current growth. The organic analysis contains data on chlorophyll a and $\mathrm{b}$, total chlorophyll, moisture percentage of dry weight, and nitrogen percentage for each sample.

The inorganic chemistry of the conifers consisted of two different analytical methods, Inductively Coupled Plasma Emission Spectrometry (ICP-ES) and Inductively Coupled Plasma Mass Spectrometry (ICP-MS) respectively. The ICPES method is less expensive and was applied to nine of ten samples in each plot. The ICP-ES method analyzed 37 elements of which 24 elements "yielded concentrations of sufficient concentration and data quality to be of value for further data evaluation, plotting and comparison with remotely sensed data" [8]. The 24 elements were: Cadmium, Copper, Manganese, Molybdenum, Nickel, Lead, Zinc, Aluminum, Arsenic, Boron, Barium, Calcium, Cobalt, Chromium, Iron, Gallium, Potassium, Lanthanum, Magnesium, Sodium, Phosphorus, Strontium, Vanadium, and Sulfur. The ICP-MS method was applied to one sample from each plot. The ICP-MS method gave an analysis of 63 elements per sample. Unlike the conifer organic chemistry, the salal organic chemistry was not split into current and noncurrent categories. The salal inorganic chemistry was analyzed using only the ICP-ES method with 22 of the 37 elements being of significant value for comparison with remotely sensed data. Table 2 lists the number of samples for each analysis source in the database.

Table 2. Number of samples for each analysis set in the GVWD acquired in September 2000.

\begin{tabular}{|l|l|}
\hline \multicolumn{1}{|c|}{ Type of Sample } & \multicolumn{1}{|c|}{$\begin{array}{c}\text { Number of } \\
\text { Samples }\end{array}$} \\
\hline Current Conifer Organic Chemistry & 450 \\
\hline $\begin{array}{l}\text { Non-Current Conifer Organic } \\
\text { Chemistry }\end{array}$ & 450 \\
\hline ICP-ES Conifer Inorganic Chemistry & 486 \\
\hline ICP-MS Conifer Inorganic Chemistry & 54 \\
\hline Salal Organic Chemistry & 197 \\
\hline Salal Inorganic Chemistry & 209 \\
\hline Total & 1846 \\
\hline
\end{tabular}

The database also contains spectral data from 3900 spectral samples taken using the ASD FieldSpec FR field spectroradiometer. Reflectance data and graphs were calculated and stored in Microsoft Excel spreadsheets. We used hyperlinks in the Access database to reference the spreadsheets, and we included a listing of target descriptions for each reflectance graph. The database contains 52 different reflectance graphs and accompanying data.

The data in the database can be searched by location (using the precision GPS data), plot number, plot name, and date. The spectral data can also be searched by target description. The chemistry data allows queries on any of the analyzed 
elements. The database is to be used to aid further analysis and comparison of the chemical and spectral properties of the GVWD test site with satellite and airborne hyperspectral data. Airborne AVIRIS acquisitions were originally planned for September 2000, but did not occur. They are expected to occur now in June 2001. Additional chemistry samples will be collected then to adjust the September data for the new environmental conditions.

\section{CHEMISTRY COMPARISONS}

The chemistry data have precise spatial coordinates. Thus, we can examine the spatial distribution of chemical properties. Fig. 3 shows the distribution of measurements of arsenic in the GVWD test site. The largest circle corresponds to a concentration of $348 \mathrm{ppm}$ and the smallest circle corresponds to a concentration of $5 \mathrm{ppm}$. Arsenic is not found in the water or in the surface soils at our plots. Therefore, it appears that Douglas Fir scavenges arsenic and lead from the air.

Fig. 4 is a plot for current Douglas Fir foliage of nitrogen percent against current total chlorophyll in $\mu \mathrm{g} / \mathrm{mg}$. The equation $\mathrm{N} \%=1.1064(\mathrm{Chl})+0.2275$ has $\mathrm{a} \mathrm{R}^{2}=0.6931$.

\section{CONCLUSIONS}

Calibration of optical remote sensing data involves the selection of uniform targets of sufficient scale as to be assured of accurate comparisons of ground and airborne or satellite pixels. Hyperspectral calibration is more complex in that a ground spectrum of the target is required. The primary advantage of hyperspectral remote sensing is that it is possible to measure the chemical properties of vegetation, such as forests. Thus, it is important to have detailed ground measurements of the chemical properties of the vegetation. These are difficult and expensive to obtain for forest canopies. This paper reports on a campaign undertaken, in support of a future EO-1 mission, to gather organic and inorganic chemical measurements in the GVWD test site (15 $\mathrm{km}$ by $23 \mathrm{~km}$ ). The relational database for EVEOSD spectra and chemistry is described and examples are presented of the spatial distribution of chemicals. Ground and helicopter sampling was done to a geometric accuracy of $1 \mathrm{~m}$.

\section{ACKNOWLEDGMENTS}

We acknowledge the cooperation of the Greater Victoria Watershed District staff and management. We are most grateful for financial support from Natural Resources Canada, the Canadian Space Agency (CSA), and Natural Sciences and Engineering Research Council (NSERC).

\section{REFERENCES}

D. G. Goodenough, D. Charlebois, P. Bhogal, M. Heyd, S. Matwin, O. Niemann, and F. Portigal, "Knowledge-Based
Imaging Spectrometer Analysis and GIS for Forestry," Proc. IGARSS'95, 464-467, Florence, Italy, 1995.

D. G. Goodenough, D. Charlebois, S. Matwin, and M. Robson, "Automating Reuse of Software for Expert System Analysis of Remote Sensing Data," IEEE Trans. on Geos. and Rem. Sens., vol. 32, pp. 525-533, 1994.

[3] K. O. Niemann, D. G. Goodenough, and P. Bhogal, "Remote Sensing of Moisture Variations in Old growth Douglas Fir," Rem. Sens. Environ., pp. (in press), 1998.

K. O. Niemann, D. G. Goodenough, A. Dyk, and A. S. Bhogal, "Pixel Unmixing for Hyperspectral Measurement of Foliar Chemistry in Pacific Northwest Coastal Forests," Proc. International Geoscience and Remote Sensing Symposium 1999 (IGARSS'99), 1, 512-514, Hamburg, Germany, 1999.

[5] A. S. Bhogal, D. G. Goodenough, A. Dyk, and K. O. Niemann, "AVIRIS Imagery for Forest Attribute Information: Anisotropic Effects and Limitations in Multi-Temporal Data," Proc. IGARSS 2000, 4, 1388-1392, Honolulu, Hawaii, 2000.

[6] J. R. Miller, H. P. White, J. M. Chen, D. R. Peddle, G. McDermid, R. A. Fournier, P. Shepherd, I. Rubinstein, J. Freemantle, R. Soffer, and E. LeDrew, "Seasonal change in understory reflectance of boreal forests and influence on canopy vegetation indices," Journal of Geophysical Research (JGR), vol. 102(D24), pp. 29475-29482, 1997.

J. R. Miller, E. W. Hare, and J. Wu, "Quantitative Characterization of the Vegetation Red Edge Reflectance," International Journal of Remote Sensing, vol. 11, pp. 1755 1773., 1990.

C. Dunn and R. Scagel, "Tree-Top Sampling and Analysis of Douglas-Fir (Pseudotsuga menziesii) in the Greater Victoria Watershed (GVWD) EVEOSD Supersite," Report Contract \#M0301 for the Pacific Forestry Centre 2000.

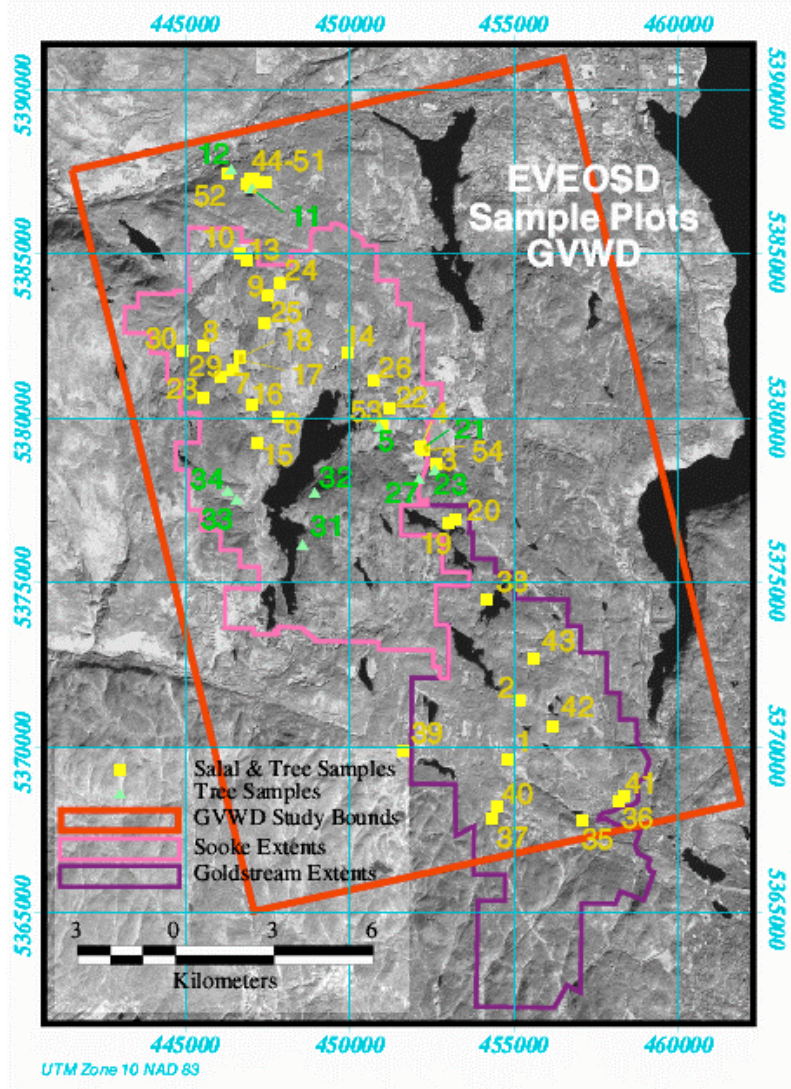

Figure 1. EVEOSD Sample Plots in the GVWD. 


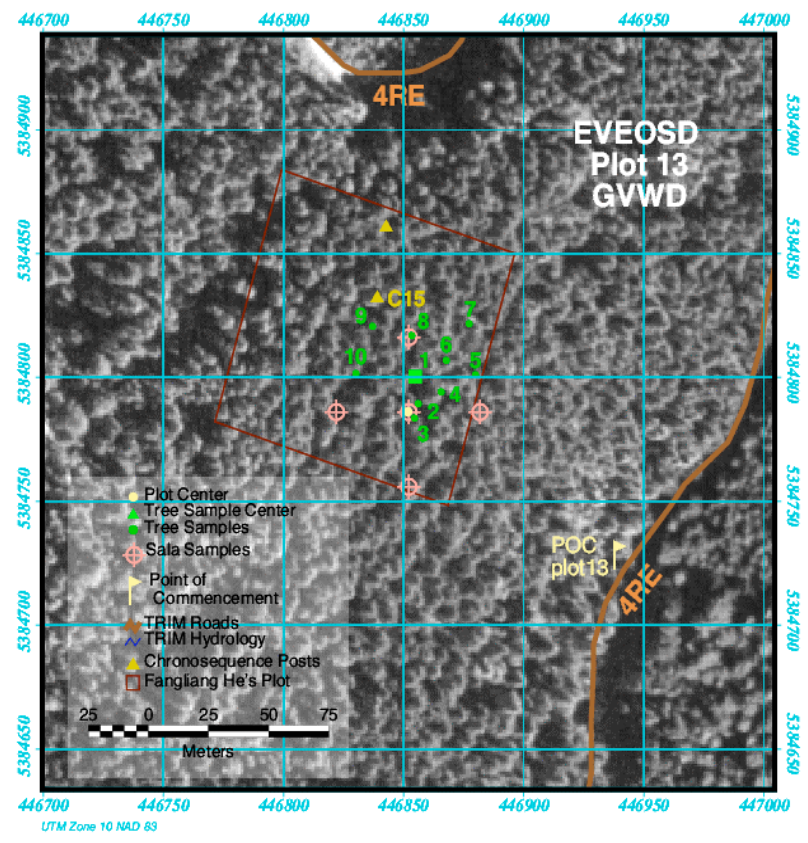

Figure 2. Detailed sampling map, EVEOSD Plot 13, Old Growth Forest with foliar (green) and salal (pink) samples.

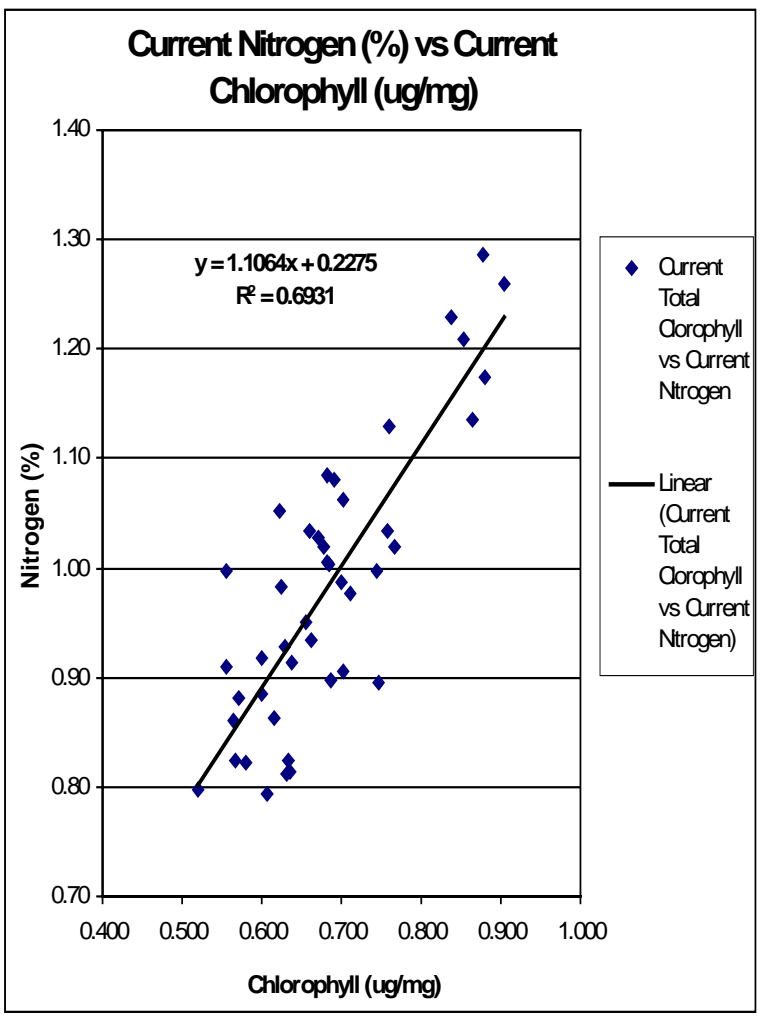

Figure 4. Nitrogen \% plotted against chlorophyll $(\mu \mathrm{g} / \mathrm{mg})$ for current Douglas Fir foliage.

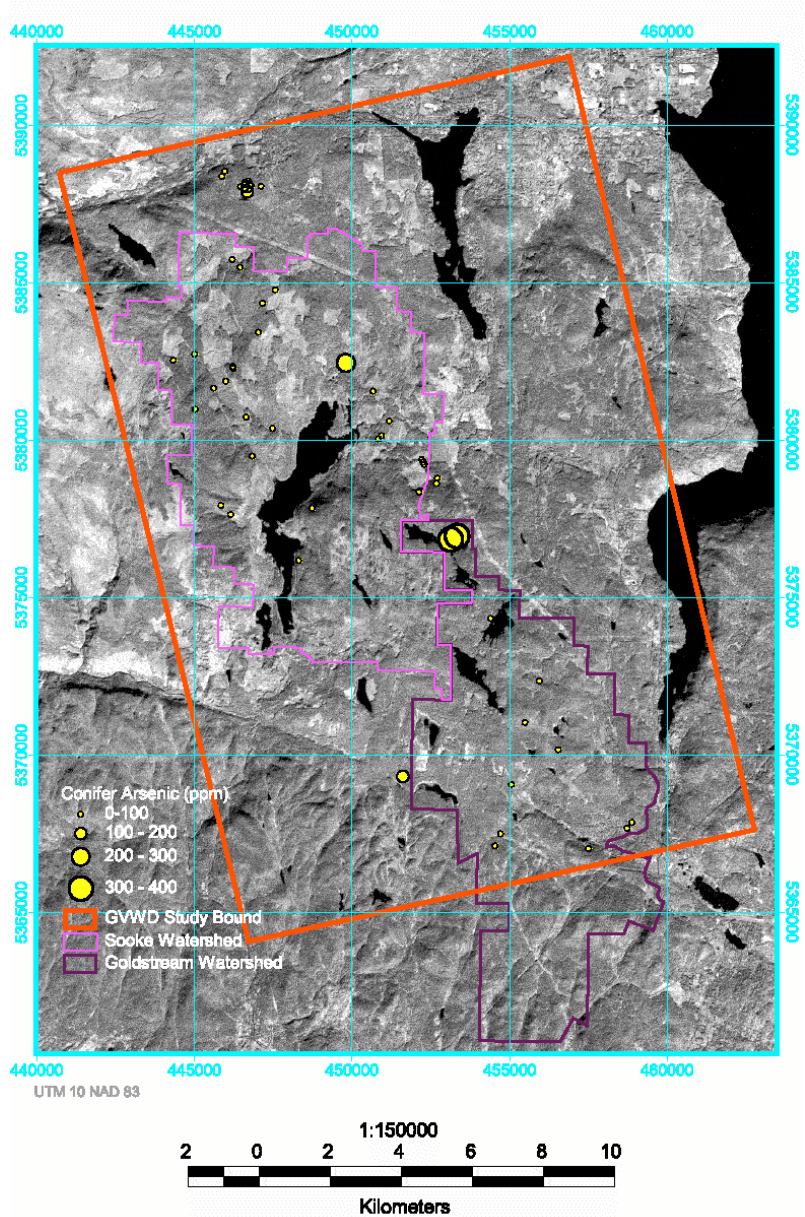

Figure 3. Arsenic concentration of foliar samples in GVWD from $5 \mathrm{ppm}$ to $348 \mathrm{ppm}$. 